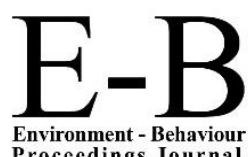

Environment - Behaviour
Procecdings Journal
AIVCE-BS-1, 2020ShahAlam

https://www.amerabra.org; https://fspu.uitm.edu.my/cebs; https://www.emasemasresources.com/ AMEABRA International Virtual Conference on Environment-Bahaviour Studies, $1^{\text {st }}$ Series cE-Bs, FSPU, Universiti Teknologi MARA, Shah Alam, 24-25 Jun 2020

\section{e-IPH}

e-International Publishing House Ltd. United Kingdom

\title{
Determinants for Healthy Lifestyle of Patients with Familial Hypercholesterolaemia
}

\author{
Salmi Razali1,3, Yap Bee Wah², Chua Yung An³, Hapizah M Nawawi ${ }^{3}$ \\ 1Department of Psychiatry, Faculty of Medicine, 3Institute of Pathology, Laboratory and Forensic Medicine (I-PPerForM) \\ Faculty of Medicine, Universiti Teknologi MARA, 47000 Sungai Buloh, Selangor, Malaysia \\ ${ }^{2}$ Advanced Analytics Engineering Centre, Faculty of Computer and Mathematical Sciences, \\ Universiti Teknologi MARA Shah Alam, Malaysia
}

drsalmi@gmail.com, yapbeewah@salam.uitm.edu.my, yungan.chua@gmail.com, hapizah.nawawi@gmail.com

Tel.: +603-61265000

\begin{abstract}
Lifestyle modification is a pivotal intervention for Familial Hypercholesterolaemia (FH). This study aims to describe the lifestyles (physical activity and healthy diet) and their associations with sociodemography, illness characteristics, psychological elements, family support and level of barrier. 100 participants were given Pro forma questionnaires to assess sociodemography and illness characteristics. The lifestyles, psychological elements, family support and level of barrier were assessed using the Theory of Planned Behaviour questionnaire. The determinants of healthy lifestyles include the status of receiving treatment, level of barrier and intention for behavioural change. The findings may inform the strategy for lifestyle modification of $\mathrm{FH}$ patients.
\end{abstract}

Keywords: Familial Hypercholesterolaemia; lifestyle; physical activity; healthy diet

eISSN: 2398-4287@ 2020. The Authors. Published for AMER ABRA cE-Bs by e-International Publishing House, Ltd., UK. This is an open access article under the CC BYNC-ND license (http://creativecommons.org/licenses/by-nc-nd/4.0). Peer-review under responsibility of AMER (Association of Malaysian Environment-Behaviour Researchers), ABRA (Association of Behavioural Researchers on Asians) and cE-Bs (Centre for Environment-Behaviour Studies), Faculty of Architecture, Planning \& Surveying, Universiti Teknologi MARA, Malaysia.

DOI: https://doi.org/10.21834/ebpj.v5i14.2335

\subsection{Introduction}

Familial Hypercholesterolaemia (FH) is an important risk factor for cardiovascular diseases (CVDs); the leading causes of morbidity and mortality worldwide. Globally, the prevalence of FH is around 1: 500-200. In Malaysia, recent National Health and Morbidity Survey (2019) indicated that hypercholesterolemia is one of the significant risks for cardiovascular disease. The prevalence of hypercholesterolemia is 38.1\%; indicating one in three Malaysians may have this condition (National Institute of Health, Malaysia (2020). Other major risk factors are diabetes mellitus, obesity and hypertension. FH is an essential cause of hypercholesterolemia among the Malaysian population, with an estimated frequency of 1:100 (Vallejo-Vaz et al., 2018). Researchers have identified various causes of hypercholesterolaemia; one of the essential causes is primary hypercholesterolaemia, including $\mathrm{FH}$. It is primary dyslipidaemia which involved a genetic mutation in cellular transportation and catabolism of LDL-C, such as LDL-receptor (LDLR), apolipoprotein B (APOB), proprotein convertase subtilisin/kexin type 9 (PCSK9) and low-density lipoprotein receptor adaptor protein 1 genes (LDLRAP1) (AlKhateeb et al., 2016). On the other hand, secondary dyslipidaemia is often associated with the elevated LDL-C which most often caused by external factors including taking high-fat diet, lack of physical activity and exercise leading to obesity, smoking or, from other diseases such as hypothyroidism, liver disease or chronic renal failure (Al-Khateeb et al., 2016).

$\mathrm{FH}$ may lead to severe CVDs and other complications, and if untreated, $\mathrm{FH}$ patients will suffer reduced life expectancy by up to 30 years compared those without FH (Alonso, Mata, \& Mata, 2005). Without early treatment, CVDs and other complications caused FH patients to have a poor quality of life (Razali, Ismail, Yung et al., 2019). Hence, preventive measures of CVDs including taking lipid-

eISSN: 2398-4287@ 2020. The Authors. Published for AMER ABRA cE-Bs by e-International Publishing House, Ltd., UK. This is an open access article under the CC BYNC-ND license (http://creativecommons.org/licenses/by-nc-nd/4.0). Peer-review under responsibility of AMER (Association of Malaysian Environment-Behaviour Researchers), ABRA (Association of Behavioural Researchers on Asians) and cE-Bs (Centre for Environment-Behaviour Studies), Faculty of Architecture, Planning \& Surveying, Universiti Teknologi MARA, Malaysia.

DOI: https://doi.org/10.21834/ebpj.v5i14.2335 
lowering agents, stress management and lifestyle interventions (such as taking healthy diet, performing vigorous physical activities, exercise and smoking cessation) are vital. Moreover, positive illness perceptions and belief on the illness is crucial for adherence to treatment and early preventive measures (Razali, Ismail, \& Abdullah et al., 2019). In order to ensure life-long behavioural modification, the underlying health-related psychological process that shapes the intention for behavioural changes must well be understood to inform effective interventions (Hagger et al., 2016). These underlying psychological processes in behavioural change has been explained by many theories (Bandura, 1986; Prochaska, 1998; Ajzen, 1985). One of the popular theories is the Theory of Planned Behaviour (TPB) which was introduced by Icek Ajzen in 1985. The theory suggested that a 'behaviour' is dependent on one's intention to perform the behaviour and the intention is dependent on the attitude (beliefs and values about the outcome of the behaviour), subjective norms (beliefs about what other people think the person should do or general social pressure) and perceived behavioural control or one's perceptions of his ability or feelings of self-efficacy to perform the behaviour (Ajzen, 1985, 2011). To date, there is still sparse knowledge and awareness of these concepts among both the public, patients and health practitioners. Hence, this study aims to: i) describe the lifestyle of $\mathrm{FH}$ patients (including engagement with physical activity and taking healthy diet) and, ii) determine the associations between the lifestyles and sociodemographic factors, illness characteristics, the underlying health-related psychological elements (including intention, attitude, subjective norms and perceived behavioural control), family support and level of barrier.

\subsection{Methodology}

\subsection{Study design, setting and data collection}

This study was a cross-sectional study which recruited participants from the Specialist Lipid and Coronary Risk Prevention Clinics in a Teaching Hospital in Malaysia. Convenient sampling was used, and the participants aged 18 years or more who were patients diagnosed with FH according to Dutch Lipid Clinic (DLC) criteria were enrolled. The DLC criteria is a validated set of criteria based on the patient's family history of premature cardiovascular disease (CVD) in their first-degree relatives, personal coronary heart disease (CHD) history, their untreated LDL-C level and physical signs such as tendon xanthomata or arcus cornealis prior to the age of 45 . Prior to the commencement of the study, written informed consent was granted from all participants. The study was approved by the Institutional Research Ethics committee (600-RMI (5/1/6).

\subsection{Assessment tools}

Sociodemographic background, illness characteristics, family support and barrier for performing physical activity and taking healthy diet were assessed using self-reported pro forma questionnaires. Sociodemographic variables include information regarding gender, age, marital status, level of education and their total household income per month. Illness characteristics include the presence of CVDs, type of CVDs (including coronary heart disease, angina, stroke atherosclerosis and peripheral vascular disease) treatment for $\mathrm{FH}$, and risk factors for coronary artery disease (including smoking status, high blood pressure, depression and high stress). The underlying healthrelated psychological concepts (such as intention, attitude, subjective norms, perceived behavioural control) were assessed using questionnaires constructed based on the TPB (Ajzen, 2011).

\subsection{Statistical Analysis}

Statistical Package for the Social Sciences version 24 was used to analyse the data. Data were mostly recategorised into dichotomous data. The associations between sociodemographic factors, illness characteristics, domains of TPB (attitude, subjective norms, perceived behavioural control and intention), family support and level of barrier and domains of lifestyles (engagement with physical activity and taking healthy diet) were analysed using Chi-Square analysis. Multiple regressions were carried out to identify the determinants of engagement with physical activity and taking healthy diet.

\subsection{Results}

\subsection{Sociodemography}

A total of hundred participants ( $37 \%$ male and $63 \%$ female), predominantly in the late forties (mean \pm SD: $49.8 \pm 11.4$ years old) and evermarried individuals (92\%) participated in the study. They were mainly from a lower socioeconomic position with which $55 \%$ of the participants had a total household income less than RM3000 a month, and $52 \%$ of studied participants attained only up to the level of secondary education (Refer to Table 1).

\subsection{IIIness characteristics}

Of the total participants who had FH, $41 \%$ had CVDs; mainly coronary heart disease ( $n=35 ; 85.4 \%)$, angina $(n=8 ; 19.5 \%)$, atherosclerosis $(n=4 ; 9.8 \%)$, stroke $(n=4 ; 9.8 \%)$ and one participant had peripheral arterial disease. About two-thirds $(69 \%)$ of the participants received lipid-lowering agents. More than a third (40\%) of the participants had hypertension, $13 \%$ were smokers, and $8 \%$ reported feeling stressed up and complained of feeling depressed. 


\subsection{Lifestyle pattern}

The majority $66(68.8 \%)$ of $\mathrm{FH}$ patients in the study reported that they had been taking healthy diet. However, less than half of the patients reported that they engaged with physical activity (Figure 1). Only $13(13 \%)$ of FH patients in the study were still smoking during the study period.

Table 1: Sociodemographic Background of the Participants

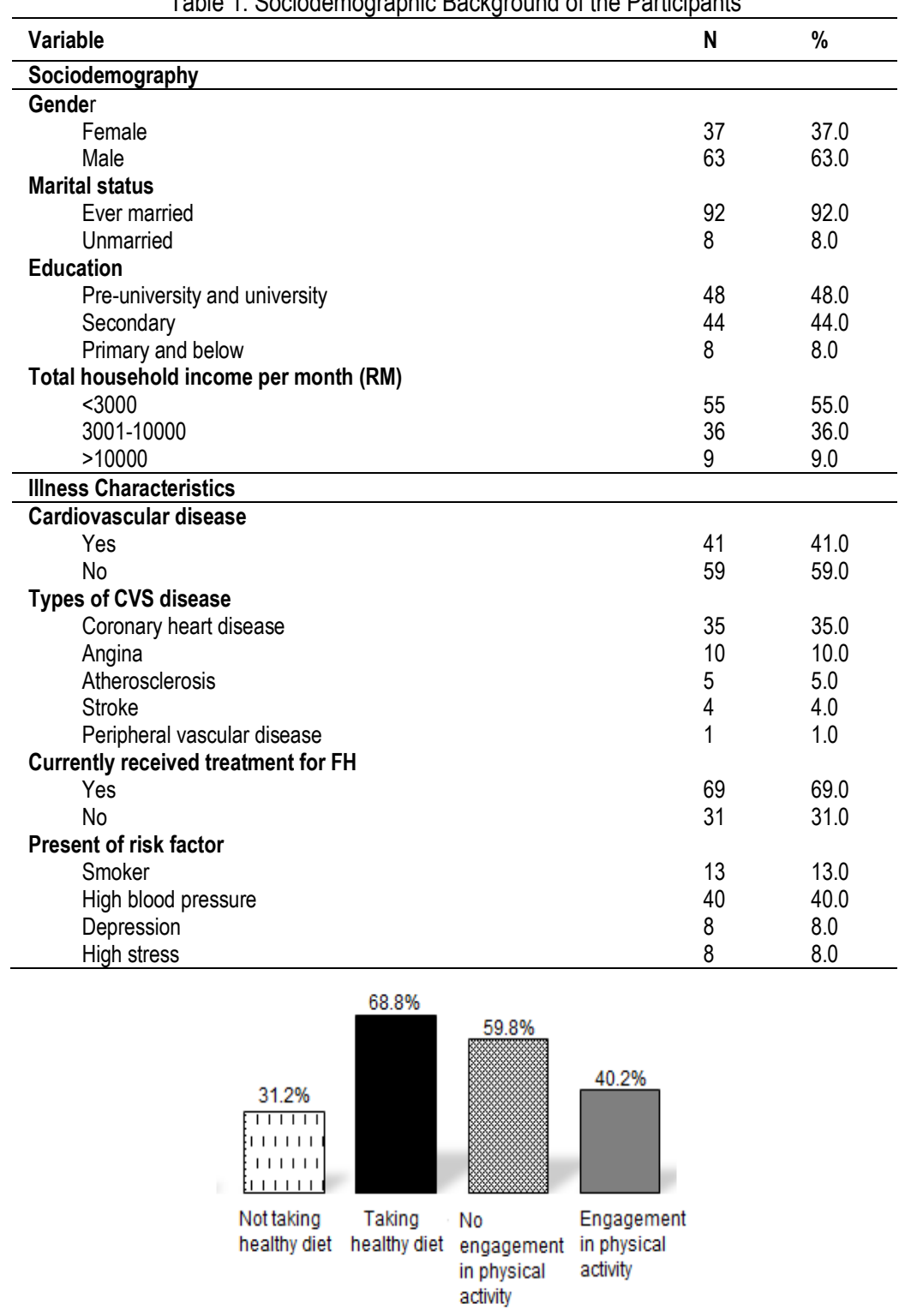

Figure 1. Percentages of the Lifestyles (Engagement in Physical Activity and Taking Healthy Diet)

\subsection{Determinants of the lifestyle of FH patients}

\subsubsection{Factors for engagement in physical activity}

There were significant associations between the engagement with physical activities, and the status of receiving treatment, the intention to perform the physical activity and the level of barrier. $\mathrm{FH}$ patients engaged in physical activity were significantly higher $\left(\mathrm{X}^{2}(1)=4.895\right.$; $p=0.027)$ among those who were receiving treatment $(n=22 ; 56.4 \%)$ than those who were not $(n=17(43.6 \%)$. Those who engaged in physical activity were also significantly higher $\left(X^{2}(1)=11.379 ; p=0.001 ;\right.$ Yates correction: $\left.X^{2}(1)=9.734 ; p=0.002\right)$ among $F H$ patients who had intention $(n=37 ; 68.3 \%)$ than those who had no intention to perform the physical activity $(n=18(32.7 \%)$. Moreover, in terms of the level of barrier, the patients engaged in physical activity were significantly higher $\left(X^{2}(1)=15.303 ; p=0.000\right.$; Yates correction: $\left(X^{2}\right.$ $(1)=13.663 ; p=0.000)$ among those who had a low level of barrier $(n=34 ; 87.2 \%)$ than those who had a high level of barrier $(n=5 ; 12.8 \%)$ (Refer to Table 2).

Multiple logistic regressions were performed to identify the determinants for engagement with physical activity. The independent variables included in the model development were gender, age, total household income, presence of CVD, the status of receiving treatment, intention, family support and the level of barrier. The Omnibus test for model coefficient showed that the model was significant 
$\left(X^{2}(8)=34.929 ; p<0.001\right.$; the Nagelkerke $R^{2}=0.413 ;$ Cox \& Snell $\left.R^{2}=0.305\right)$ and the predictive accuracy of the model for the training sample was $78.10 \%$. There was no multicollinearity exist between independent variables; the values for tolerance were more than 0.1 , and VIF was less than 10 for each variable. The significant determinants for engagement of physical activity of the FH patients were the intention to perform $(B=2.213 ; A O R=9.145 ; p=0.020)$ and the level of barrier $(B=-1.892 ; A O R=0.151 ; p=0.002)$.

Table 2: Engagement with Physical Activity and Possible Contributing Factors

\begin{tabular}{|c|c|c|}
\hline \multirow{2}{*}{ Variable: } & \multicolumn{2}{|c|}{ Physical activity } \\
\hline & Yes & No \\
\hline \multicolumn{3}{|l|}{ Sociodemography } \\
\hline Age & $38(49.5 \pm 13.2)$ & $58(49.9 \pm 9.3)$ \\
\hline \multicolumn{3}{|l|}{ Gender } \\
\hline Female & $12(30.8 \%)$ & $24(41.4 \%)$ \\
\hline Male & $27(69.2 \%)$ & $34(58.6 \%)$ \\
\hline \multicolumn{3}{|l|}{ Marital status } \\
\hline Ever married & $35(89.7 \%)$ & $55(94.8 \%)$ \\
\hline Unmarried & $4(10.3 \%)$ & $3(5.2 \%)$ \\
\hline \multicolumn{3}{|l|}{ Education } \\
\hline Pre-university and university & $34(61.8 \%)$ & $11(26.8 \%)$ \\
\hline Secondary & $17(30.9 \%)$ & $27(65.9 \%)$ \\
\hline Primary and below & $4(7.3 \%)$ & $3(7.3 \%)$ \\
\hline \multicolumn{3}{|l|}{ Income (RM) } \\
\hline$<3000$ & $21(53.8 \%)$ & $32(55.2 \%)$ \\
\hline $3001-10000$ & $17(43.6 \%)$ & $18(32.1 \%)$ \\
\hline$>10000$ & $1(2.6 \%)$ & $8(13.8 \%)$ \\
\hline \multicolumn{3}{|l|}{ Illness Characteristics } \\
\hline \multicolumn{3}{|l|}{ CVD } \\
\hline Presence & $15(87.2 \%)$ & $26(44.8 \%)$ \\
\hline Absent & $24(12.8 \%)$ & $32(55.2 \%)$ \\
\hline \multicolumn{3}{|l|}{ Receiving FH Treatment * } \\
\hline Yes & $22(56.4 \%)$ & $45(77.5 \%)$ \\
\hline No & $17(43.6 \%)$ & $13(22.4 \%)$ \\
\hline \multicolumn{3}{|l|}{ Comorbidity } \\
\hline Single & $14(93.3 \%)$ & $20(71.4 \%)$ \\
\hline Presence & $1(6.7 \%)$ & $8(28.6 \%)$ \\
\hline \multicolumn{3}{|l|}{ Risk Factors } \\
\hline Single & $17(85,0 \%)$ & $23(71.9 \%)$ \\
\hline Multiple & $3(15.0 \%)$ & $9(2.8 \%)$ \\
\hline \multicolumn{3}{|c|}{ Psychological element in Theory of Planned Behaviour } \\
\hline \multicolumn{3}{|c|}{ Subjective norms } \\
\hline Yes & $38(97.4 \%)$ & $55(96.5 \%)$ \\
\hline No & $1(0.6 \%)$ & $2(3.5 \%)$ \\
\hline \multicolumn{3}{|l|}{ Perceived behavioural control } \\
\hline Yes & $37(94.9 \%)$ & $55(98.2 \%)$ \\
\hline No & $2(5.1 \%)$ & $1(1.8 \%)$ \\
\hline \multicolumn{3}{|l|}{ Attitude } \\
\hline Good & $39(100.0 \%)$ & $56(96.6 \%)$ \\
\hline Bad & $0(0 \%)$ & $2(3.4 \%)$ \\
\hline Excited & $39(100.0 \%)$ & $55(58.5 \%)$ \\
\hline Boring & $0(0 \%)$ & $3(100 \%)$ \\
\hline Fun & $39(100.0 \%)$ & $53(94.8 \%)$ \\
\hline Unpleasant & $0(0.0 \%)$ & $5(5.2 \%)$ \\
\hline \multicolumn{3}{|l|}{ Intention** } \\
\hline Yes & $37(68.3 \%)$ & $40(95.2 \%)$ \\
\hline No & $18(32.7 \%)$ & $2(4.7 \%)$ \\
\hline \multicolumn{3}{|l|}{ Family Support } \\
\hline Yes & $35(89.7 \%)$ & $45(77.6 \%)$ \\
\hline No & $4(10.3 \%)$ & $13(22.4 \%)$ \\
\hline \multicolumn{3}{|l|}{ Level of Barrier ${ }^{* *}$} \\
\hline Low & $34(87.2 \%)$ & $28(48.3 \%)$ \\
\hline High & $5(12.8 \%)$ & $30(51.7 \%)$ \\
\hline
\end{tabular}

\subsubsection{Factors for taking healthy diet}

There were significant associations between taking healthy diet and the status of receiving treatment and the level of barrier. FH patients taking healthy diet were significantly higher $\left(X^{2}(1)=8.107 ; p=0.004\right)$ among those who were receiving treatment $(n=57 ; 78.8 \%)$ than those who were not $(n=14 ; 21.2 \%)$. Those who were taking healthy diet were also significantly higher $\left(X^{2}(1)=7.822 ; p=0.005 ;\right.$ Yates correction: $\left(X^{2}(1)=6.465 ; p=0.011\right)$ among FH patients who had low level of barrier $(n=55 ; 83.3 \%)$ than those who had high level of barrier $(n=11 ; 16.7 \%)$. Refer to Table 3 for further details. 
In the model development, we included gender, age, total household income, presence of CVD, the status of receiving treatment, and level of barrier in the analysis. The Omnibus test for model coefficient showed that the model was significant $\left(X^{2}(6)=19.086\right.$; $p<0.001$; the Nagelkerke $R^{2}=0.257$; Cox \& Snell $R^{2}=0.182$ ) and the predictive accuracy of the model for the training sample was $75.80 \%$. There was no multicollinearity exist between independent variables; the values for tolerance were more than 0.1 , and VIF was less than 10 for each variable. The significant determinants for taking healthy diet in $\mathrm{FH}$ patients were the status of receiving treatment $(B=1.376$; $A O R=3.961 ; p=0.024)$ and the level of barrier $(B=-1.650 ; A O R=0.192 ; p=0.003)$.

Table 3: Status of Taking Healthy Diet and Possible Contributing Factors

\begin{tabular}{|c|c|c|}
\hline \multirow{2}{*}{ Variables } & \multicolumn{2}{|c|}{ Healthy Diet } \\
\hline & Yes & No \\
\hline \multicolumn{3}{|l|}{ Sociodemography } \\
\hline Age & $38(49.5 \pm 13.2)$ & $58(49.9 \pm 9.3)$ \\
\hline \multicolumn{3}{|l|}{ Gender } \\
\hline Female & $12(30.8 \%)$ & $24(41.4 \%)$ \\
\hline Male & $27(69.2 \%)$ & $34(58.6 \%)$ \\
\hline \multicolumn{3}{|l|}{ Marital status } \\
\hline Ever married & $35(89.7 \%)$ & $55(94.8 \%)$ \\
\hline Unmarried & $4(10.3 \%)$ & $3(51.7 \%)$ \\
\hline \multicolumn{3}{|l|}{ Education } \\
\hline Pre-university and university & $34(61.8 \%)$ & $11(26.8 \%)$ \\
\hline Secondary & $17(30.9 \%)$ & $27(65.9 \%)$ \\
\hline Primary and below & $4(7.3 \%)$ & $3(7.3 \%)$ \\
\hline \multicolumn{3}{|l|}{ Income (RM) } \\
\hline$<3000$ & $21(53.8 \%)$ & $32(55.2 \%)$ \\
\hline $3001-10000$ & $17(43.6 \%)$ & $18(31.0 \%)$ \\
\hline$>10000$ & $1(2.6 \%)$ & $8(13.8 \%)$ \\
\hline \multicolumn{3}{|l|}{ Illness Characteristics } \\
\hline \multicolumn{3}{|l|}{ CVD } \\
\hline Presence & $31(47.0 \%)$ & $10(33.3 \%)$ \\
\hline Absent & $35(53.0 \%)$ & $20(66.7 \%)$ \\
\hline \multicolumn{3}{|l|}{ Receiving FH Treatment * } \\
\hline Yes & $52(78.8 \%)$ & $15(50.0 \%)$ \\
\hline No & $14(21.2 \%)$ & $15(50.0 \%)$ \\
\hline \multicolumn{3}{|l|}{ Comorbidity } \\
\hline Single & $26(81.3 \%)$ & $8(72.7 \%)$ \\
\hline Presence & $6(18.7 \%)$ & $3(27.3 \%)$ \\
\hline \multicolumn{3}{|l|}{ Risk Factors } \\
\hline Single & $31(77.5 \%)$ & $9(75.0 \%)$ \\
\hline Multiple & $9(2.25 \%)$ & $3(25.0 \%)$ \\
\hline \multicolumn{3}{|c|}{ Psychological element in Theory of Planned Behaviour } \\
\hline \multicolumn{3}{|l|}{ Subjective norms } \\
\hline Yes & $64(97.0 \%)$ & $28(96.6 \%)$ \\
\hline No & $2(3.0 \%)$ & $1(3.4 \%)$ \\
\hline \multicolumn{3}{|l|}{ Perceived behavioural control } \\
\hline Yes & $64(97.0 \%)$ & $28(93.3 \%)$ \\
\hline No & $2(3.0 \%)$ & $2(6.7 \%)$ \\
\hline \multicolumn{3}{|l|}{ Attitude } \\
\hline Good & $66(71.7 \%)$ & $26(86.7 \%)$ \\
\hline Bad & $0(0 \%)$ & $4(13.3 \%)$ \\
\hline Excited & $64(98.5 \%)$ & $25(83.3 .1 \%)$ \\
\hline Boring & $1(1.5 \%)$ & $5(16.7 \%)$ \\
\hline Fun & $62(96.8 \%)$ & $24(80.0 \%)$ \\
\hline Unpleasant & $2(3.1 \%)$ & $6(20.0 \%)$ \\
\hline \multicolumn{3}{|l|}{ Intention } \\
\hline Yes & $64(97.0 \%)$ & $22(73.3 \%)$ \\
\hline No & $2(3.0 \%)$ & $8(26,7 \%)$ \\
\hline \multicolumn{3}{|l|}{ Family Support } \\
\hline Yes & $62(94.0 \%)$ & $23(79.3 \%)$ \\
\hline No & $4(6.0 \%)$ & $6(20.6 \%)$ \\
\hline \multicolumn{3}{|l|}{ Level of Barrier** } \\
\hline Low & $55(83.3 \%)$ & $17(56.7 \%)$ \\
\hline High & $11(16.7 \%)$ & $13(43.3 \%)$ \\
\hline
\end{tabular}

\subsection{Discussion}

This study is essential to inform clinicians of the possible factors that influence the lifestyles of FH patients. We found that the lifestyle of our $\mathrm{FH}$ patients relates to their illness condition, i.e. their status of receiving treatment. It is easy to speculate that those $\mathrm{FH}$ patients 
who were receiving treatment were among those who have good insight and awareness of the needs for treatment (Eriksson et al., 2006). Perhaps, the mediating factor is the fear of having the complication may motivate FH patients who were receiving treatment to have a better healthy lifestyle. FH patients who received treatment may have continuous counselling on the need for healthy lifestyle every time they visit health care facilities. It is crucial for clinicians to provide counselling on both adherence to medications and a healthy lifestyle as part of the intervention for $\mathrm{FH}$ patients.

In our study, barriers hindered FH patients from having healthy lifestyles. In terms of physical activity, a local study in managing weight problem indicated that the main barriers in performing exercise and physical activity include lack of family and friend's involvement, poor weather, lack of discipline and suitable time as well as a financial problem (Ibrahim et al., 2013). For healthy diet intake, factors such as time, food taste and price were suggested to be the main challenges to comply towards dietary counselling (Sulaiman et al., 2016). Hence, it is critical to minimise barriers to ensure that FH patients maintain their lifestyle behaviour and modification. In a study examining the barriers experienced by patients with hyperlipidaemia, a group of health providers have divided the barriers into; i) provider barriers (including poor tracking and patient follow-up, poor understanding of guidelines and the literature, controversy over guideline recommendations, poor understanding of patient needs, and inadequate training in facilitating behavioural change in patients); ii) patient barriers (including poor adherence to referrals, asymptomatic nature of the diseases, linguistic and cultural difficulties, psychosocial challenges blunting efforts to adhere, poor patient's acceptance of the disease, and difficulty of lifestyle changes); and iii) practice/system barriers (including poor multidisciplinary cooperation, documentation burdens, difficulty educating patients at the right educational level, and difficulty coordinating care with the hospital) (Cook et al., 2006). Addressing all these barriers is crucial for the comprehensive management of $\mathrm{FH}$ patients.

A few scholars in psychology have demonstrated through their proposed theory of the link between intention and lifestyle behaviour (Fishbein, 1980; Fishbein \& Ajzen, 1975; Ajzen, 1985, 1991; Triandis, 1980; Rogers, 1983). Our study supported this association and indicated that $\mathrm{FH}$ patients should have strong intention in order to engage with physical activities. In other study investigating lifestyle of FH patients using integrated psychological model, Hagger and colleagues (2016) have demonstrated that not only the intention but also attitude plays as an essential mediator for lifestyle changes in $\mathrm{FH}$ patients. Given the importance of intention in behavioural modification strategy, clinicians in particular health psychologist should enhance $\mathrm{FH}$ patients understanding on this psychological element when providing counselling on the self-management support service for FH patients.

Our findings also supported and added to other determinants that were found by other researchers who examined the lifestyle of general populations (Chan et al., 2015; Cheah \& Poh, 2014). In their studies, other factors influencing lifestyles include age, income, gender, education, marital status, region, house locality, job characteristics, and medical conditions have been suggested (Cheah \& Poh, 2014). In order to ensure FH patients have optimum quality of life, apart from practising health lifestyle, FH patients should also equipped themselves with positive perceptions and enough knowledge on the illness itself and its complications (Razali et al., 2019).

\subsection{Conclusion and Recommendations}

FH Patients who engaged with physical activity are those who were receiving treatment, experiencing a low level of barrier and had the intention to perform the physical activities. Those patients who were receiving treatment and experiencing a low level of barrier were also more likely to take a healthy diet. Further studies to understand the barriers of practising healthy lifestyle among them is crucial. Clinicians should be aware of these elements to ensure effective advice for lifestyle modification of FH patients. However, the results should be interpreted with care because this study is limited with small sample size, and we used self-perception in describing the level of engagement with physical activities and taking healthy diet. Furthermore, there are many other cultural beliefs and perceptions that may not be captured by the questionnaires that may influence the lifestyles of $\mathrm{FH}$ patients. In future, more improvement in the study methods is required for more impactful findings.

\section{Acknowledgement}

This study is funded by UiTM MITRA Grant [grant code: 600-IRMI/MYRA 5/3/MITRA (003/2017)-2)] awarded to the first and corresponding authors.

\section{References}

Ajzen, Icek (2011). The theory of planned behaviour: Reactions and reflections. Journal Psychology \& Health; 26(9); 1113-1127

Al-Khateeb, A., Hamzan, N.S., Razali, R., Froemming, GA., Rahman, T., Peng, H.B., \& Nawawi, H. (2016). Genetic Study of Low-Density Lipoprotein Receptor Gene and Apolipoprotein B-100 Gene among Malaysian Patients with Familial Hypercholesterolaemia. International Archives of Medicine, 9.

Alonso, R., Mata, N., \& Mata, P. (2005). Benefits and risks assessment of simvastatin in familial hypercholesterolaemia. Expert Opinion on Drug Safety, 4(2), $171-181$. Bandura, A. (1986). Social Foundations of Thought and Action. Englewood Cliffs, New Jersey: Prentice-Hall.

Chan, Y., Teh, Ch., Lim, K.K., Lim, K.H., Yeo, PS., Kee, C.C., Omar, M.A and Ahmad, N.A (2015). Lifestyle, chronic diseases and self-rated health among Malaysian adults: results from the 2011 National Health and Morbidity Survey; BMC Public Health, 15:754 
Cook, S., Drum, M.L., Kirchhoff, A.C., Jin, L., Levie, J., Harrison, J.F., ... Chin, M.H. (2006). Providers' Assessment of Barriers to Effective Management of Hypertension and Hyperlipidemia in Community Health Centers. Journal of Health Care for the Poor and Underserved 17(1), 70-85. doi:10.1353/hpu.2006.0021.

Eriksson, K.M., Westborg, C.J. Mats CE, and Eliasson (2006) A randomised trial of lifestyle intervention in primary healthcare for the modification of cardiovascular risk factors The Björknäs study. Scandinavian Journal of Public Health, 34 (5)

Fishbein, M., \& Ajzen, I. (1975). Belief, Attitude, Intention and Behavior: An Introduction to Theory and Research. Reading, MA: Addison-Wesley.

Fishbein, M. (1980). A theory of reasoned action: Some applications and implications. In H. Howe \& M. Page (Eds.), Nebraska Symposium on Motivation (Vol. 27, pp. 65- 116). Lincoln, NB: University of Nebraska Press.

Hagger, M.S., Hardcastle, S.J., Hingley, C., Strickland, E., Pang, J., \& Watts, G.F. (2016). Predicting self-management behaviours in familial hypercholesterolaemia using an integrated theoretical model: The impact of beliefs about illnesses and beliefs about behaviours. International Journal of Behavioral Medicine, 23(3), 282-294.

Ibrahim, S., Karim, N.A., Oon, NL, and Wan Ngah, W.Z. (2013) Perceived physical activity barriers related to body weight status and sociodemographic factors among Malaysian men in Klang Valley; BMC Public Health.13:275

National Institute of Health, Malaysia (2020), National Health and Morbidity Survey (2019). Factsheet: Noncommunicable Diseases Healthcare Demand and Health Literacy. Retrieved from http://www.iku.gov.my/images/IKU/Document/REPORT/NHMS2019/Fact_Sheet_NHMS_2019-English.pdf.

Prochaska, J., Johnson, S., \& Lee, P. (1998). The transtheoretical model of behaviour change. In S. Schumaker, E. Schron, J. Ockene \& W. McBee (Eds.), The Handbook of Health Behavior Change, 2nd ed. New York, NY: Springer.

Razali, S., Ismail, Z., Abdullah, N., and Nawawi, H.M (2019). Illness Perception of Patients with Familial Hypercholesterolaemia varies with Level of Education and Presence of Cardiovascular Disease; Environment-Behaviour Proceedings Journal; 4(10);72-78. DOI: https://doi.org/10.21834/e-bpj.v4i10.1620

Razali, S., Ismail, Z., Yung, A.C., and Nawawi, H.M (2019). Quality of Life and Its Contributing Factors in Patients with Familial Hypercholesterolaemia in Malaysia; Environment-Behaviour Proceedings Journal; 4(10); 86-92. DOI: https://doi.org/10.21834/e-bpj.v4i10.1621

Rogers, R. W. (1983). Cognitive and physiological processes in fear appeals and attitude change: A revised theory of protection motivation. In B. L. Cacioppo \& L. L. Petty (Eds), Social Psychophysiology: A Sourcebook. London: Guilford

Sulaiman, S., Abdul Manaf, Z and Shahril M.R. (2016) Compliance to Dietary Counselling in Controlling Blood Lipid and its Barriers among Dyslipidemic Individuals Journal on Advanced Science, Engineering and Information Technology 6 (5)

Triandis, H. C. (1980). Values, attitudes, and interpersonal behaviour. In H. Howe \& M. Page (Eds), Nebraska Symposium on Motivation (Vol. 27, pp. 195-259). Lincoln, NB: University of Nebraska Press.

Ying Vallejo-Vaz, A.J., De Marco, M., Stevens, C.A.T., Akram, A., Freiberger, T., Hovingh, G.K., et al. (2018). Overview of the current status of familia hypercholesterolaemia care in over 60 countries - The EAS Familial Hypercholesterolaemia Studies Collaboration (FHSC). Atherosclerosis, 277, $234-255$. 